\title{
Inheritance of Powdery Mildew Resistance in Sugar Beet Derived from Beta vulgaris subsp. maritima
}

\author{
R. T. Lewellen and J. K. Schrandt, USDA-ARS, U.S. Agricultural Research Station, 1636 E. Alisal St., Salinas, \\ CA 93905
}

\section{ABSTRACT}

Lewellen, R. T., and Schrandt, J. K. 2001. Inheritance of powdery mildew resistance in sugar beet derived from Beta vulgaris subsp. maritima. Plant Dis. 85:627-631.

Powdery mildew of sugar beet (Beta vulgaris), caused by Erysiphe polygoni, was introduced into North American in 1974. Since then, chemical control has been needed. Moderate resistance of a slow-mildewing type is known and has been used commercially. High resistance was identified recently in B. vulgaris subsp. maritima accessions WB97 and WB242 and has been backcrossed into sugar beet breeding lines. These enhanced lines were used as sources of powdery mildew resistance to determine the inheritance of resistance. Analyses of segregating testcross families showed that resistance from both sources is inherited as a single, dominant, major gene. The gene symbol $P m$ is proposed for the resistant allele. The allelism of the resistance from the two wild beet sources was not determined. Pm conditions a high level of resistance, but disease developed on matured leaves late in the season. This late development of mildew on lines and the slow-mildewing trait in susceptible, recurrent lines tended to obfuscate discrete disease ratings.

Additional keywords: beet, Erysiphe betae, germ plasm enhancement, prebreeding

Powdery mildew of sugar beet (Beta vulgaris L.), caused by Erysiphe polygoni DC (E. betae (Vanha) Weltzien), became important in the United States in 1974 after apparently being introduced into the Imperial Valley (8). Most traditional North American sugar beet cultivars and germ plasm proved to be highly susceptible. Yield losses greater than $30 \%$ were measured (9). Powdery mildew has been successfully controlled with fungicides $(1,2)$. In the western United States, one or more fungicide applications are recommended for every crop. To reduce the reliance on fungicides for disease control, resistant cultivars are needed. Partial resistance of a slow-mildewing type has been identified in sugar beet germ plasm (12). Breeding lines with partial resistance have been developed, e.g., C39 (3). Commercial hybrids with partial resistance also have been made available to growers by the sugar beet industry. A search of Beta genetic resources identified high levels of resistance in $B$. vulgaris subsp. maritima (L.) Arcang. On the basis of field observations, McFarlane (7) identified accessions with high resistance. Subsequently, in controlled green-

Corresponding author: R. T. Lewellen

E-mail: rlewellen@salinas.ars.usda.gov

Accepted for publication 16 February 2001.

Publication no. D-2001-0413-01R

This article is in the public domain and not copyrightable. It may be freely reprinted with customary crediting of the source. The American Phytopathological Society, 2001. house evaluations, Whitney (11) confirmed that two wild beet accessions, WB97 and WB242, had individual plants that showed high resistance. Neither a high level of resistance nor major gene resistance to $E$. polygoni in sugar beet has been previously reported. The objective of this research was to determine the inheritance of powdery mildew resistance from enhanced sugar beet germ plasm with high resistance to powdery mildew from the WB97 and WB242 sources. A preliminary report on the inheritance of resistance has been made (5), and resistant sugar beet germ plasm has been released (4). In addition, molecular genetic markers linked to resistance gene(s) from WB242 may have been identified (10).

\section{MATERIALS AND METHODS}

Plant material. Wild beet accessions WB97 and WB242 were used as sources of resistance to powdery mildew. WB97 was accessed by the Salinas station in 1968 from the Japan Sugarbeet Improvement Foundation which, in turn, obtained this line in 1963 as WB46 from a collection at Wageningen, the Netherlands. McFarlane increased seed in 1977 and 1978 (7). His field tests in 1980 showed that WB97 was an annual of mixed plant types, and individual plants were highly resistant to powdery mildew (7). WB242 was received from Bergen op Zoom, the Netherlands, in 1974. Passport data showed that it was originally collected as $B$. vulgaris subsp. maritima from the Loire River Estuary in France and that it may be partially resistant to sugar beet cyst nematode (Heterodera schachtii Schmidt). WB242 was increased at Salinas in 1979. In McFarlane's 1980 field test, WB242 was mostly annual, variable for plant type with both erect and procumbent stem growth, and most plants were highly resistant to powdery mildew. The phylogenic relationship between WB97 and WB242 is unknown.

After the initial crosses of WB97 and WB242 with sugar beet, a series of backcrosses was made to transfer resistance to E. polygoni into sugar beet and eliminate as quickly as possible the weedy traits of B. vulgaris subsp. maritima (4). Resistance

Table 1. Scores of sugar beet plots and distribution of plants in 1997 for reaction to powdery mildew in a susceptible check, recurrent parent, and source lines and $\chi^{2}$ tests for goodness-of-fit to $1 \mathrm{R}: 1 \mathrm{~S}$ and $3 \mathrm{R}: 1 \mathrm{~S}$ ratios for $\mathrm{F}_{1}$ and $\mathrm{F}_{2}$ lines, respectively

\begin{tabular}{|c|c|c|c|c|c|c|c|}
\hline & & \multicolumn{6}{|c|}{ Reaction to powdery mildew } \\
\hline \multicolumn{2}{|c|}{ Check and parental source } & Score $^{x}$ & $\mathbf{R}^{\mathbf{y}}$ & $\mathbf{S}^{\mathbf{y}}$ & Ratio & $\chi^{2}$ & $\boldsymbol{P}$ \\
\hline \multicolumn{8}{|l|}{ Check } \\
\hline US H11 & Susceptible check & 7.9 & 11 & 403 & & & \\
\hline \multicolumn{8}{|c|}{ Recurrent and testcross parent } \\
\hline C37 & Susceptible parental line & 7.8 & 18 & 163 & & & \\
\hline \multicolumn{8}{|c|}{ Backcross derived source lines } \\
\hline P403 & $\mathrm{BC}_{3} \mathrm{~F}_{1}(\mathrm{C} 37 / / 4 \times \mathrm{WB} 97)$ & 6.0 & 24 & 24 & $1: 1$ & 0.00 & $>0.99$ \\
\hline P603 & $\mathrm{BC}_{3} \mathrm{~F}_{2}$ PMR sel. P403 & 4.3 & 40 & 11 & $3: 1$ & 0.32 & $0.50-0.90$ \\
\hline P404 & $\mathrm{BC}_{3} \mathrm{~F}_{1}(\mathrm{C} 37 / / 4 \times \mathrm{WB} 242)$ & 5.3 & 26 & 21 & $1: 1$ & 0.53 & $0.10-0.50$ \\
\hline P604 & $\mathrm{BC}_{3} \mathrm{~F}_{2}$ PMR sel. P404 & 3.8 & 43 & 6 & $3: 1$ & 4.25 & $0.01-0.05^{* z}$ \\
\hline
\end{tabular}

x Powdery mildew scored on a plot basis ( 2 to 32 plots per line) on 29 July 1997, on a scale of 0 to 9 where each increment equals a $10 \%$ increase and $9=90$ to $100 \%$ of visible mature leaf area covered with mildew.

y Number of plants counted on 21 July 1997 without pulling plants and before powdery mildew reached its peak severity, where $\mathrm{R}=$ resistant and $\mathrm{S}=$ susceptible to powdery mildew. $\mathrm{R}=$ plants scored 0 to $1 ; \mathrm{S}=$ plants scored 2 to 9 on a 0 to 9 scale.

$\mathrm{z} *, P \leq 0.05$. 
Table 2. Distribution of sugar beet plants for reaction to powdery mildew on 8 August 1997 in testcross families derived from WB97 and WB242 sources of resistance and $\chi^{2}$ tests for goodness-of-fit to $1 \mathrm{R}: 1 \mathrm{~S}$ ratio

\begin{tabular}{|c|c|c|c|c|}
\hline \multirow[b]{2}{*}{ Family no. } & \multicolumn{4}{|c|}{ Testcross (1:1) } \\
\hline & $\mathbf{R}^{\mathbf{w}}$ & $\mathbf{S}^{\mathbf{w}}$ & $\chi^{2}$ & $P$ \\
\hline \multicolumn{5}{|c|}{$6201=\mathrm{C} 37 \times \mathrm{P} 403(\mathrm{WB} 97)^{\mathrm{x}}$} \\
\hline-1 & 24 & 29 & 0.47 & $0.10-0.50$ \\
\hline-4 & 20 & 29 & 1.65 & $0.10-0.50$ \\
\hline-6 & 29 & 23 & 0.69 & $0.10-0.50$ \\
\hline-11 & 14 & 29 & 5.23 & $0.01-0.05 * \mathrm{y}$ \\
\hline-22 & 20 & 14 & 1.06 & $0.10-0.50$ \\
\hline-23 & 14 & 8 & 1.64 & $0.10-0.50$ \\
\hline-24 & 7 & 3 & 1.60 & $0.10-0.50$ \\
\hline Total & & & 12.34 & $0.05-0.10$ \\
\hline Pooled & 128 & 135 & 0.24 & $0.50-0.90$ \\
\hline Heterogeneity & & & 12.10 & $0.05-0.10$ \\
\hline 8 susc. families ${ }^{z}$ & 9 & 357 & & \\
\hline \multicolumn{5}{|c|}{$6205=\mathrm{C} 37 \times \mathrm{P} 404(\mathrm{WB} 242)^{\mathrm{x}}$} \\
\hline-31 & 20 & 18 & 0.11 & $0.50-0.90$ \\
\hline-32 & 20 & 18 & 0.11 & $0.50-0.90$ \\
\hline-33 & 27 & 24 & 0.18 & $0.50-0.90$ \\
\hline-34 & 11 & 10 & 0.05 & $0.50-0.90$ \\
\hline-35 & 27 & 17 & 2.27 & $0.10-0.50$ \\
\hline-36 & 16 & 25 & 1.98 & $0.10-0.50$ \\
\hline-37 & 14 & 16 & 0.13 & $0.50-0.90$ \\
\hline-38 & 31 & 26 & 0.44 & $0.50-0.90$ \\
\hline-39 & 26 & 27 & 0.02 & $0.50-0.90$ \\
\hline-41 & 15 & 7 & 2.91 & $0.05-0.10$ \\
\hline-42 & 11 & 12 & 0.04 & $0.50-0.90$ \\
\hline-43 & 3 & 6 & 1.00 & $0.10-0.50$ \\
\hline-45 & 16 & 11 & 0.93 & $0.10-0.50$ \\
\hline-46 & 21 & 22 & 0.02 & $0.50-0.90$ \\
\hline-47 & 21 & 19 & 0.10 & $0.50-0.90$ \\
\hline-48 & 35 & 12 & 11.26 & $<0.01 * *$ \\
\hline-49 & 13 & 10 & 0.39 & $0.50-0.90$ \\
\hline-51 & 25 & 29 & 0.30 & $0.50-0.90$ \\
\hline Total & & & 22.24 & $0.10-0.50$ \\
\hline Pooled & 352 & 309 & 2.80 & $0.05-0.10$ \\
\hline Heterogeneity & & & 19.44 & $0.10-0.50$ \\
\hline
\end{tabular}

${ }^{\text {w}}$ Counts made on pulled and separated plants on 8 August 1997, when powdery mildew appeared to be at its peak severity, where $\mathrm{R}=$ resistant and $\mathrm{S}=$ susceptible. $\mathrm{R}=$ plants scored 0 to $1 ; \mathrm{S}=$ plants scored 2 to 9 on a 0 to 9 scale.

${ }^{x}$ See Table 1 for pedigrees.

y $*, P \leq 0.05$.**, $P \leq 0.01$.

${ }^{\mathrm{z}}$ Eight 6201 testcross families judged to be homozygous susceptible to powdery mildew.

Table 3. Scores of sugar beet plots and distribution of plants in 1999 for reaction to powdery mildew in checks, recurrent parents, and source lines

\begin{tabular}{llccc}
\hline & & \multicolumn{2}{c}{ Reaction to powdery mildew } \\
\cline { 2 - 5 } Checks and parental sources & Score $^{\mathbf{v}}$ & $\mathbf{R}^{\mathbf{w}}$ & $\mathbf{S}^{\mathbf{w}}$ \\
\hline WB242 & Wild beet source of resistance & 0.0 & All $^{\mathrm{x}}$ & \\
C37 & Susceptible parental line & 6.7 & & All $^{\mathrm{y}}$ \\
C78 & Susceptible parental line & 5.0 & & $\mathrm{All}^{\mathrm{y}}$ \\
Y71 & Susceptible parental line & 5.9 & & All $^{\mathrm{y}}$ \\
Y79-1 & Susceptible parental line & 6.4 & & All $^{\mathrm{y}}$ \\
Backcross derived source lines & & & \\
P603 & $\mathrm{BC}_{3} \mathrm{~F}_{2}$ PMR sel. P403 (WB97 source) & 3.9 & & \\
P604 & $\mathrm{BC}_{3} \mathrm{~F}_{2}$ PMR sel. P404 (WB242 source) & 4.3 & & \\
P813 & $\mathrm{BC}_{4} \mathrm{~F}_{2}(\mathrm{C} 37 / / 5 \times$ WB97) & 5.4 & $38^{\mathrm{z}}$ & $67^{\mathrm{z}}$ \\
P814 & $\mathrm{BC}_{4} \mathrm{~F}_{2}(\mathrm{C} 37 / / 5 \times$ WB242) & 4.7 & $51^{\mathrm{z}}$ & $49^{\mathrm{z}}$ \\
\hline
\end{tabular}

${ }^{v}$ Mean of four ratings at approximately weekly intervals from 12 August 1999 to 31 August 1999 for powdery mildew reactions scored on a plot basis from 0 to 9 , where each increment equals a $10 \%$ increase and $9=90$ to $100 \%$ of visible mature leaf area covered with mildew.

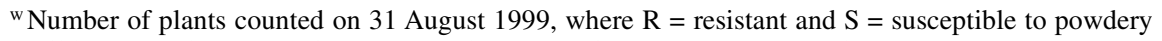
mildew. $\mathrm{R}=$ plants scored 0 to $1 ; \mathrm{S}=$ plants scored 2 to 9 on a 0 to 9 scale.

${ }^{x}$ At time plots were scored, powdery mildew was not evident but subsequently developed mildly from September through October.

${ }^{y}$ Individual plants within a plot were not pulled and counted but examined in place for occurrence of resistant individuals.

${ }^{\mathrm{z}} \mathrm{F}_{2}$ produced from unselected $\mathrm{F}_{1}$ plants with unknown frequency of resistant allele. to powdery mildew was not selected after every backcross, but selection was practiced often enough to maintain resistance in the backcross lines. For backcross lines P403 and P404 (Table 1), the final backcross was made from plants selected for resistance. These backcross lines were developed in a self-sterile C37 (6) background from WB97 and WB242 sources of resistance, respectively. Self-sterile $\left(S^{s} S^{s}\right)$ plants will not self under paper bags in the greenhouse at Salinas. The $\mathrm{F}_{2}$ lines P603 and $\mathrm{P} 604$ were individually produced in mass from plants of P403 and P404, respectively, which had been selected in the field for resistance to powdery mildew (Table 1).

To create testcross families for the 1997 inheritance of resistance study, backcross lines P403 and P404 were grown in the field at Salinas in an August 1995 planting. Powdery mildew incidence was very mild under these late-planted conditions, and escapes were likely. Plants without visible mildew were selected. To initiate flowering, selected plants were photothermally induced in cold rooms and used to produce testcrosses. Plants from parental line C37 were randomly obtained from stecklings produced in overwintered nurseries in Oregon without their reaction to powdery mildew having been verified.

Testcross pollinations were made in the greenhouse under paper bags. Plants of P403 and P404 were individually crossed to single plants of C37 to produce testcross families 6201 and 6205, respectively (Table 2). Seed from each plant of the pairwise cross was maintained separately as pair-cross reciprocals. Identity of seed from each plant and cross for all testcrosses was maintained.

Plants from lines P403 and P603 for testcrosses evaluated in 1999 were used for the WB97 source. Plants from lines P404 and P604 were used for the WB242 source. Using essentially the same procedure as described above, plants from P403, P603, P404, and P604 were backcrossed individually in the greenhouse to plants from line C79-1, Y71, or C78 (Table 3). Powdery mildew susceptible lines C79-1, Y71, and $\mathrm{C} 78$ are similar to $\mathrm{C} 37$ but have resistance to rhizomania caused by Beet necrotic yellow vein virus. Compared with families tested in 1997, testcross families evaluated in 1999 represented one or two additional backcrosses to sugar beet (Tables 4 and 5). Some of the individual backcross plants that were used to make the testcrosses evaluated in 1999 had not been selected for resistance to powdery mildew. Thus, some testcross families would not have resistance and would be uniformly susceptible. These susceptible families were identified in the 1999 field test, and individual plants within plots were not scored or counted. Likewise, a few $\mathrm{F}_{2}$ plants used from $\mathrm{P} 603$ or P604 could have been homozygous resistant. Families that 
were uniformly resistant to powdery mildew also were not scored or counted nor included in the 1999 data set.

Inoculation. All evaluations were made in the field at Salinas, CA. Since 1974, when powdery mildew was first observed (8), moderate to severe epiphytotics have naturally occurred at Salinas. However, powdery mildew did not appear in late June, as usual, in the 1999 field trial. To assure powdery mildew infection, sugar beet leaves with powdery mildew infection were collected from Tracy and Merced areas. On 14 July, to make the inoculation, leaves with developing conidia were shaken over plants in adjacent, susceptible spreader rows upwind of the trial area. By 22 July, powdery mildew infection was observed throughout the Salinas trial fields. This infection, though, was probably the result of the usual, natural infection sequence in California.

Resistance evaluation. Checks, parental lines, and testcross families were tested in field plots at Salinas (Tables 1 to 5). In 1997, the highly susceptible genotype US H11 was used as a susceptible check and in spreader rows around the trial area. Parental line C37 was systematically placed throughout the trial. Plots of the $F_{1}$ source populations $\mathrm{P} 403$ and $\mathrm{P} 404$, along with $\mathrm{F}_{2}$ versions P603 and P604, were systematically placed among the plots of the testcross families (Table 1). Depending upon seed quantities available, each testcross family was represented in one to three plots. Reciprocal seed from each plant of a pair-wise cross was tested in separate plots. The counts for the corresponding reciprocals and repetitions were combined for each family.

The 1997 test was planted 4 March. Individual plots consisted of single rows 72 $\mathrm{cm}$ wide and $3 \mathrm{~m}$ long with a $0.6-\mathrm{m}$ alley. Following over-seeding, plants were carefully thinned and singled to about $15-\mathrm{cm}$ spacing. Best cultural practices with sprinkler irrigation were used to obtain vigorous plants. Powdery mildew first appeared in late June. Whole plots were scored subjectively for reaction to powdery mildew on a scale of 0 to 9 where $0=$ no evidence of mildew, each increment equals a $10 \%$ increase, and $9=90$ to $100 \%$ of visible, mature leaf area covered with mildew. Scoring was done on 29 July 1997. In 1999, the test was planted on 13 April. The same design and procedures as used in 1997 were followed.

Plants were counted on 21 July 1997 in all plots (Table 1). Because a few plants within known, fully susceptible checks still appeared resistant and it was very difficult to accurately separate individual plants within a plot, all testcross families were recounted by carefully pulling and separating plants on 8 August, when powdery mildew was uniformly severe. Plants were placed in two classes: resistant and susceptible. Plants counted as resistant were rated
0 or 1 , where mildew was very sparse and visible only on the oldest leaves. This criterion for resistance was based upon observations in the segregating source populations where reaction to powdery mildew fell into fairly discrete resistant and susceptible types. In 1999, counts were made on pulled plants on 31 August. In 1999, disease development occurred much later and disease reactions were less severe, more variable, and less discrete between resistant and susceptible types (Table 3). The same scoring procedure was followed, but misclassifications likely were higher.

Data analysis. Count data for disease reaction for each progeny family were examined. Because backcross-generated plants were used to make the testcrosses, they were either resistant or susceptible. Families that appeared to have discrete segregation into resistant and susceptible classes were individually analyzed for the appropriate goodness-of-fit to a single, dominant gene model using $\chi^{2}$ analysis (Tables 1, 2, 4, and 5). Families from common source lines were pooled, and $\chi^{2}$ tests for heterogeneity were calculated. For 1997, counts for families that appeared to be fully susceptible or had very low numbers of resistant plants were pooled (Table 2).

\section{RESULTS AND DISCUSSION}

High levels of resistance to E. polygoni found in B. vulgaris subsp. maritima accessions WB97 and WB242 were transferred to sugar beet by backcrossing. These enhanced sugar beet lines continued to show discrete segregation for reaction to powdery mildew (Tables 1 and 3 ). Individual plants from the enhanced sugar beet lines were used in controlled crosspollinations to determine segregation patterns. In 1997, testcross families segregated for resistance or were fully susceptible (Table 2). Families that segregated were tested for goodness-of-fit to the appropriate ratios. Most segregating families fit the pattern expected for a single, dominant gene (Table 2). The results of this field test showed that resistance to powdery mildew was inherited as a single, dominant factor in both sources. The tests for heterogeneity also showed that each set of segregating families represented a single population. The name and gene symbol for this resistance factor are proposed to be $P m$. If research shows that $P m$ from the two sources are different alleles or at different loci, numerals could be added as needed to the Pm symbol.

Table 4. Distribution of sugar beet plants on 31 August 1999 for reaction to powdery mildew on testcross families derived from WB97 source of resistance and $\chi^{2}$ tests for goodness-of-fit to $1 \mathrm{R}: 1 \mathrm{~S}$ ratio

\begin{tabular}{|c|c|c|c|c|}
\hline \multirow[b]{2}{*}{ Family no. ${ }^{x}$} & \multicolumn{4}{|c|}{ Testcross (1:1) } \\
\hline & $\mathbf{R}^{\mathbf{y}}$ & $\mathbf{S}^{\mathbf{y}}$ & $\chi^{2}$ & $\boldsymbol{P}$ \\
\hline \multicolumn{5}{|c|}{$\mathrm{P} 809=\mathrm{BC}_{5} \mathrm{~F}_{1}[\mathrm{C} 78 \times(\mathrm{C} 79-1 \times \mathrm{P} 403)]$} \\
\hline$-1 \quad-1$ & 15 & 32 & 6.15 & $0.01-0.05 * \mathrm{z}$ \\
\hline-2 & 3 & 8 & 2.27 & $0.10-0.50$ \\
\hline-5 & 20 & 28 & 1.33 & $0.10-0.50$ \\
\hline-6 & 16 & 21 & 0.68 & $0.10-0.50$ \\
\hline-7 & 6 & 12 & 2.00 & $0.10-0.50$ \\
\hline-10 & 7 & 15 & 2.91 & $0.05-0.10$ \\
\hline-12 & 26 & 19 & 1.09 & $0.10-0.50$ \\
\hline-14 & 20 & 30 & 2.00 & $0.10-0.50$ \\
\hline-15 & 15 & 12 & 0.33 & $0.50-0.90$ \\
\hline Total & & & 18.76 & $0.01-0.05^{*}$ \\
\hline Pooled & 128 & 177 & 7.87 & $<0.01 * *$ \\
\hline Heterogeneity & & & 10.89 & $0.10-0.50$ \\
\hline \multicolumn{5}{|c|}{$\mathrm{P} 815=\mathrm{BC}_{4} \mathrm{~F}_{1}(\mathrm{C} 78 \times \mathrm{P} 603)$} \\
\hline-1 & 11 & 14 & 0.36 & $0.50-0.90$ \\
\hline-4 & 21 & 21 & 0.00 & $>0.99$ \\
\hline-11 & 22 & 26 & 0.33 & $0.50-0.90$ \\
\hline-14 & 6 & 10 & 1.00 & $0.10-0.50$ \\
\hline-15 & 17 & 33 & 5.12 & $0.01-0.05 *$ \\
\hline Total & & & 6.81 & $0.10-0.50$ \\
\hline Pooled & 77 & 104 & 4.03 & $0.01-0.05 *$ \\
\hline Heterogeneity & & & 2.78 & $0.50-0.90$ \\
\hline \multicolumn{5}{|c|}{$\mathrm{P} 807=\mathrm{BC}_{5} \mathrm{~F}_{1}[\mathrm{C} 78 \times(\mathrm{Y} 71 \times \mathrm{P} 603)]$} \\
\hline-2 & 27 & 26 & 0.02 & $0.50-0.90$ \\
\hline-6 & 29 & 23 & 0.69 & $0.10-0.50$ \\
\hline-7 & 28 & 14 & 4.67 & $0.01-0.05 *$ \\
\hline-8 & 19 & 40 & 7.48 & $<0.01 * *$ \\
\hline Total & & & 12.85 & $0.01-0.05 *$ \\
\hline Pooled & 103 & 103 & 0.00 & $>0.99$ \\
\hline Heterogeneity & & & 12.85 & $<0.01 * *$ \\
\hline
\end{tabular}

x See Tables 1 and 3 for pedigrees.

y Counts made on pulled and separated plants on 31 August 1999 when powdery mildew appeared to be at its peak severity, where $\mathrm{R}=$ resistant and $\mathrm{S}=$ susceptible to powdery mildew. $\mathrm{R}=$ plants scored 0 to $1 ; \mathrm{S}=$ plants scored 2 to 9 on a 0 to 9 scale.

z *, $P \leq 0.05$. **, $P \leq 0.01$. 
The 1999 field tests of breeding lines and backcross-derived sources of powdery mildew resistance showed less discrete segregation into resistant and susceptible classes (Table 3 ). Whereas the $B$. vulgaris subsp. maritima source WB242 was highly resistant, the susceptible, recurrent sugar beet lines were susceptible (Table 3). When scored on a plot basis, the segregating backcross-derived lines appeared to be moderately susceptible, with the resistant plants being visually overwhelmed by the susceptible plants. However, when individual plants were dug, separated, scored, and counted, fairly discrete segregation was again evithe segregating testcrosses evaluated in 1999 generally fit a $1 \mathrm{R}: 1 \mathrm{~S}$ ratio (Tables 4 and 5) and supported the hypothesis that resistance to $E$. polygoni from WB97 (Table 4) and WB242 (Table 5) is inherited in the manner of a single dominant factor. There was a tendency, however, for the distribution of WB97-derived testcrosses to be skewed toward susceptibility (Table 4) and the WB242-derived testcrosses to be skewed toward resistance (Table 5). Particularly for testcross families within the P816 backcrosses dent (Tables 3 to 5). The distribution of

(Table 5), there was a poor fit to a single factor model.

The reasons for the poor fit of the P816 families are unknown but could be due to several factors. Recurrent parent C78 is not as susceptible as C37 or the other susceptible parents and has been selected and observed to be a slow-mildewing type (Table 3). Under the conditions of the 1999 trial, counts may have been made before all slow-mildewing, susceptible plants expressed symptoms. C37 and the other recurrent parents were chosen in part because they are known to be highly self-sterile $\left(S^{s} S^{S}\right)$. If, in the P604 materials that were used to produce the P816 testcrosses, selffertility $\left(S^{f}\right)$ had been inadvertently incorporated, the tested seed lots could be mixtures of both testcross and $S_{1}$ families leading to ratings that ranged from $1 \mathrm{R}: 1 \mathrm{~S}$ to 3R:1S. The poor fit of these P816 families is not considered to be sufficient to reject the single, dominant allele model for resistance to powdery mildew. There remains sufficient evidence in the other 1997 and 1999 evaluations to accept the single, major gene hypothesis to explain most of the variability for resistance to E. polygoni. In the 1999 evaluation, the late development of the powdery mildew epiphytotic and the

Table 5. Distribution of sugar beet plants on 31 August 1999 for reaction to powdery mildew in testcross families derived from WB242 source of resistance and $\chi^{2}$ tests for goodness-of-fit to 1R:1S ratio

\begin{tabular}{|c|c|c|c|c|}
\hline \multirow[b]{2}{*}{ Family no. ${ }^{x}$} & \multicolumn{4}{|c|}{ Testcross (1:1) } \\
\hline & $\mathbf{R}^{\mathbf{y}}$ & $\mathbf{S}^{\mathbf{y}}$ & $\chi^{2}$ & $\boldsymbol{P}$ \\
\hline \multicolumn{5}{|c|}{$\mathrm{P} 810=\mathrm{BC}_{5} \mathrm{~F}_{1}[\mathrm{C} 78 \times(\mathrm{C} 79-1 \times \mathrm{P} 404)]$} \\
\hline-1 & 20 & 12 & 2.00 & $0.10-0.50$ \\
\hline-2 & 22 & 18 & 0.40 & $0.50-0.90$ \\
\hline-3 & 27 & 15 & 3.43 & $0.05-0.10$ \\
\hline-4 & 13 & 19 & 1.13 & $0.10-0.50$ \\
\hline-5 & 22 & 11 & 3.67 & $0.05-0.10$ \\
\hline-7 & 29 & 20 & 1.65 & $0.10-0.50$ \\
\hline-9 & 14 & 18 & 0.50 & $0.10-0.50$ \\
\hline-10 & 21 & 24 & 0.20 & $0.50-0.90$ \\
\hline-26 & 30 & 20 & 2.00 & $0.10-0.50$ \\
\hline-27 & 30 & 24 & 0.67 & $0.10-0.50$ \\
\hline-28 & 17 & 23 & 0.90 & $0.10-0.50$ \\
\hline Total & & & 16.54 & $0.10-0.50$ \\
\hline Pooled & 245 & 204 & 3.74 & $0.05-0.10$ \\
\hline Heterogeneity & & & 12.80 & $0.10-0.50$ \\
\hline \multicolumn{5}{|c|}{$\mathrm{P} 808=\mathrm{BC}_{5} \mathrm{~F}_{1}[\mathrm{C} 78 \times(\mathrm{Y} 71 \times \mathrm{P} 604)]$} \\
\hline-7 & 22 & 24 & 0.09 & $0.50-0.90$ \\
\hline \multicolumn{5}{|c|}{$\mathrm{P} 816=\mathrm{BC}_{4} \mathrm{~F}_{1}(\mathrm{C} 78 \times \mathrm{P} 604)$} \\
\hline-3 & 34 & 12 & 10.52 & $<0.01 * * \mathrm{z}$ \\
\hline-6 & 34 & 18 & 4.92 & $0.01-0.05 *$ \\
\hline-8 & 36 & 15 & 8.65 & $<0.01 * *$ \\
\hline-11 & 29 & 8 & 11.92 & $<0.01 * *$ \\
\hline-14 & 29 & 20 & 1.65 & $0.10-0.50$ \\
\hline-16 & 24 & 16 & 1.60 & $0.10-0.50$ \\
\hline-17 & 20 & 9 & 4.17 & $0.01-0.05 *$ \\
\hline-18 & 26 & 24 & 0.08 & $0.50-0.90$ \\
\hline-19 & 20 & 13 & 1.48 & $0.10-0.50$ \\
\hline Total & & & 44.99 & $<0.01 * *$ \\
\hline Pooled & 252 & 135 & 35.37 & $<0.01 * *$ \\
\hline Heterogeneity & & & 9.62 & $0.10-0.50$ \\
\hline
\end{tabular}

${ }^{x}$ See Tables 1 and 3 for pedigrees.

y Counts made on pulled and separated plants on 31 August 1999 when powdery mildew appeared to be at its peak severity, where $\mathrm{R}=$ resistant and $\mathrm{S}=$ susceptible to powdery mildew. $\mathrm{R}=$ plants scored 0 to $1 ; \mathrm{S}=$ plants scored 2 to 9 on a 0 to 9 scale.

$\mathrm{z} *, P \leq 0.05$.**, $P \leq 0.01$. natural variability in disease development on individual plants within a plot or trial also could have contributed to scoring errors when the entire trial was lifted and evaluated on one specific day.

To our knowledge, resistance derived from genes found in WB97 and WB242 has never been used commercially in sugar beet. Dominant, major gene resistance to powdery mildew in crop plants has been notorious for lack of durability. Because resistance conditioned by $\mathrm{Pm}$ has not been deployed beyond a few research plots, there has been little selection pressure for virulence in E. polygoni. In the field trials at Salinas through 1997, there was no evidence of virulent isolates. However, in 1999, after the testcross plots were harvested, mildew was observed in nonharvested checks and enhanced breeding lines. By late October 1999, even WB242 had developed mildew symptoms. Even though symptoms appeared to be mild, it blurred the prior discrete differences between resistant and susceptible plants. Further observations and tests with $P m$ resistant materials will be needed to determine if this is due to a virulent race of E. polygoni or a physiological change in matured $\mathrm{Pm}$ resistant leaves that allows light to moderate disease development. When Whitney (11) evaluated $B$. vulgaris subsp. maritima germ plasm accessions in the greenhouse, he reported much the same type of late development of E. polygoni on the most resistant plants.

\section{ACKNOWLEDGMENTS}

We thank J. A. Orozco and D. L. Lara for technical assistance, L. C. Wing for data analysis, and M. F. McQueen for manuscript preparation.

\section{LITERATURE CITED}

1. Hills, F. J., Chiarappa, L., and Geng, S. 1980. Powdery mildew of sugar beet: Disease and crop loss assessment. Phytopathology 70:680682.

2. Hills, F. J., Nikolich, G. A., and Leach, L. D. 1985. Sterol-inhibiting fungicides for control of sugar beet powdery mildew, methods and rates of application and evidence of growth regulation. Plant Dis. 69:257-261.

3. Lewellen, R. T. 1995. Registration of sugarbeet germplasm lines with multiple disease resistance: C39, C39R, C39R-6, C47, C47R, C93, and C94. Crop Sci. 35:596-597.

4. Lewellen, R. T. 2000. Registration of powdery mildew resistant sugarbeet germplasms CP01 and CP02. Crop Sci. 40:1515.

5. Lewellen, R. T., and Schrandt, J. K. 1999. Inheritance of resistance to powdery mildew in sugarbeet derived from Beta maritima. J. Sugar Beet Res. 36:76.

6. Lewellen, R. T., Whitney, E. D., and Skoyen, I. O. 1985. Registration of C37 sugarbeet parental line. Crop Sci. 25:375.

7. McFarlane, J. S. 1982. Beta Germplasm Preservation. Nov. 1982. 152 p. USDA, ARS, National Genetic Resources Program. Germplasm Resources Information Network (GRIN). Online Database. National Germplasm Resources Laboratory, Beltsville, MD.

8. Ruppel, E. G., Hills, F. J., and Mumford, D. L. 1975. Epidemiological observations on the sugarbeet powdery mildew epiphytotic in 
western USA in 1974. Plant Dis. Rep. 59:283286.

9. Skoyen, I. O., Lewellen, R. T., and McFarlane, J. S. 1975. Effect of powdery mildew on sugarbeet production in the Salinas Valley of California. Plant Dis. Rep. 59:506510.
10. Weiland, J. J., and Lewellen, R. T. 1999. Generation of molecular genetic markers associated with resistance to powdery mildew (Erysiphe polygoni DC) in sugarbeet (Beta vulgaris). 9th Int. Congr., July 1999. Int. Soc. Plant-Microbe Interact. p. 215.

11. Whitney, E. D. 1989. Beta maritima as a source of powdery mildew resistance in sugar beet. Plant Dis. 73:487-489.

12. Whitney, E. D., Lewellen, R. T., and Skoyen, I. O. 1983. Reaction of sugar beet to powdery mildew: Genetic variation, association among testing procedures, and results of resistance breeding. Phytopathology 73:182-185. 